\title{
STUDY OF THE POSSIBILITY OF POLYTYPE 3C SILICON CARBIDE BULK CRYSTALS GROWING FOR USE IN POWER DEVICES
}

\author{
${ }^{1,2}$ Lebedev Alexander Alexandrovich and ${ }^{1}$ Bulat Pavel Viktorovich \\ ${ }^{1}$ Saint-Petersburg National Research, \\ University of Information Technologies, Mechanics and Optics, Saint-Petersburg, Russia \\ ${ }^{2}$ Ioffe Physical Technical Institute, Saint-Petersburg, 194021, 26 Polytekhnicheskaya, Russia
}

Received 2014-05-06; Revised 2014-09-12; Accepted 2014-11-02

\begin{abstract}
Due to its electro-physical parameters, the silicon carbide is a promising material for power devices, including the microwave range. In recent years there has been considerable progress in the development of power devices, based on $\mathrm{SiC}$. Serious problem, which hinders the widespread commercialization of $\mathrm{SiC}$ bipolar power devices, is the $\mathrm{p}-\mathrm{n}$ structures degradation during high densities of passing forward current. In 1981 the blue SiC LED's emission spectrum over time degradation was detected. Later, after the creation of power rectifier diodes, based on $\mathrm{SiC}$, it was found that their characteristics are also deteriorated with increase of operating time. It was found that the cause of degradation are the so-called "Stacking Faults" (SF) -i.e., the formation of cubic $\mathrm{SiC}$ layers inside the hexagonal $\mathrm{SiC}$ diodes during direct current flow through them. However, it is easy to assume that this degradation mechanism is absent in devices, completely based on cubic polytype 3C-SiC. This study is dedicated to the study of possibility of creating device heterostructures based on $3 \mathrm{C}$-SiC. It is shown that the heterojunction between $\mathrm{SiC}$ polytypes may be more structurally perfect than heterojunctions between semiconductors with different chemical nature. The conclusion on perspectivity of SiC-based heterostructures application in modern electronic devices is made.
\end{abstract}

Keywords: Cubic Silicon Carbide, Polytype, Sublimation Epitaxy, Hetero-Polytype Structure, 3C-SiC

\section{INTRODUCTION}

It is known that due to its electro-physical parameters, the silicon carbide is a very promising material for manufacturing power devices, including the $\mathrm{HF}$ range. $\mathrm{SiC}$ has a high breakdown energy (Ebr $\sim 3 \mathrm{MV} / \mathrm{cm})$, high thermal conductivity $(\sim 3.8 \mathrm{~W} / \mathrm{cm} \mathrm{deg})$ and high electrons saturation velocity $\left(\sim 2.5 \cdot 107 \mathrm{sm} \mathrm{sec}^{-1}\right)$. Furthermore, SiCbased devices are capable to operate at high temperatures $\left(850^{\circ} \mathrm{C}\right)$. In recent years there has been considerable progress in the development of power devices, based on $\mathrm{SiC}$ of microwave range (Cooper et al., 1998). In addition to its unique electrical properties, the silicon carbide has the ability to crystallize in different modifications (polytypes). Polytypes of $\mathrm{SiC}$, having the same chemical nature, can vary greatly in their electro-physical parameters and appearance (Fig. 1). In recent years, the world's interest in the obtaining and investigation of hetero-polytype structures, based on silicon carbide, increased.

Serious problem, which hinders the widespread commercialization of $\mathrm{SiC}$ bipolar power devices, is the p-n structures degradation during high densities of passing forward current. Zeither and Theeis (1981) the blue SiC LED's emission spectrum over time degradation was detected. In the emission spectrum the peak in the green region of the spectrum appeared, which was also spatially localized on the diode working plane. The authors explained their results by the formation of $3 \mathrm{C}-\mathrm{SiC}$ inclusions inside $6 \mathrm{H}-\mathrm{SiC}$ polytype in the p-n structures under the influence of forward current.

Corresponding Author: Bulat Pavel Viktorovich, Saint-Petersburg National Research, University of Information Technologies, Mechanics and Optics, Saint-Petersburg, Russia 


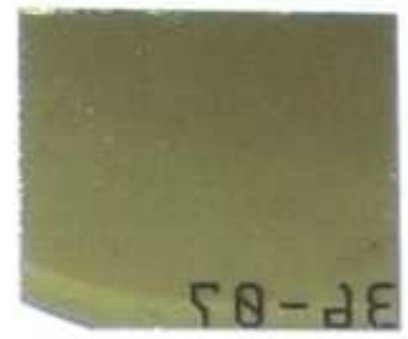

A
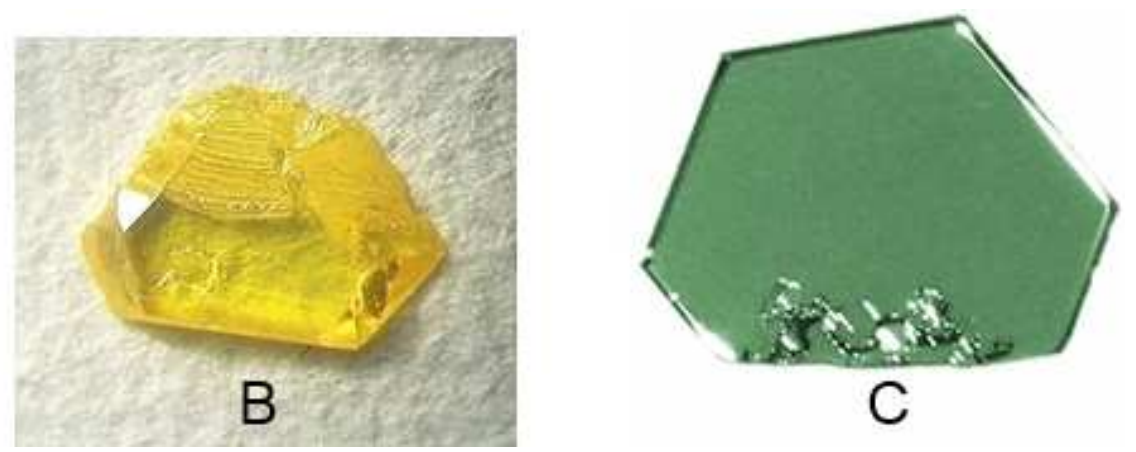

Fig. 1. $\mathrm{SiC}$ crystals of different polytypes (a) $4 \mathrm{H}-\mathrm{SiC}$ (b) $3 \mathrm{C}-\mathrm{SiC}$ (c) $6 \mathrm{H}-\mathrm{SiC}$

Later, after the creation of power rectifier diodes, based on $\mathrm{SiC}$, it was found that their characteristics were also deteriorated with increasing operating time. This is reflected in the increase of leakage currents, lowering of breakdown voltage during the reverse inclusion and increase of diode forward resistance (Bergman et al., 2001).

Research of this phenomenon has been the subject of many publications and it have found that the cause of degradation are the so-called "Stacking Faults" (SF), i.e., the formation of cubic $\mathrm{SiC}$ layers inside the hexagonal $\mathrm{SiC}$ of $4 \mathrm{H}$ or $6 \mathrm{H}$ polytypes during the forward current flowing through it (Mao et al., 2001). It turned out that the energy, dissipated during non-radiative recombination of electron-hole pair in $\mathrm{SiC}$, is sufficient to overcome the barrier, corresponding to a shift of an atom in a different position. I.e., there was a rearrangement of hexagonal polytype latticedisplacement of the atom form hexagonal positions the crystal lattice into cubic ones-the formation of cubic polytype layer. As a starting point of SF growth served the dislocation, located in the volume of the epitaxial layer or at the interface between epitaxial layer and substrate. SF is actually a quantum well of more narrowbandgap 3C-SiC inside hexagonal $\mathrm{SiC}$, causing intense recombination and consequently, a decrease in the lifetime and increase of the device's base region series resistance. Under the influence of direct current the linear dimensions of SF increased rapidly, parallel to the crystal axis of the crystal. When SF reaches the metallurgical boundary of $p-n$ transition a complete degradation of the device occurs.

The degradation, associated with the formation of SF, is currently one of the major problems in the development of bipolar devices, based on SiC. However, it is easy to assume that this degradation mechanism will not be present in devices, based on $3 \mathrm{C}-\mathrm{SiC}$. A cubic silicon carbide is the most narrow-bandgappolytypes of $\mathrm{SiC}$ and, in any case, the structural defects cannot form quantum wells in it. However, until now this assumption has no reliable experimental confirmation. For this there are two main reasons:

- Lack of 3C-SiC substrates of considerable size available on the market

- Very low structural perfection of the 3C-SiC layer, grown by $\mathrm{CVD}$ method on $\mathrm{Si}$ substrates or hexagonal SiCpolytypes

It is planned to develop the technology of $3 \mathrm{C}-\mathrm{SiC}$ substrates manufacturing, which can be used for the production of power devices, based on silicon carbide that would be unaffected by the degradation, associated with the formation of SF.

Thus, it will fix the problem that hinders wide industrial production of power devices, based on silicon carbide.

\section{SIC POLYTYPICITY}

The progress in the development of silicon carbide technology, achieved in past 20 years, allowed the creation almost of all types of semiconductor devices on its basis. Along with an established industrial manufacturing of $\mathrm{SiC}$ substrates the producing of Schottky diodes with a breakdown voltage of $600 \mathrm{~V}$ and direct currents up to $20 \mathrm{~A}$ have started in recent years. Is expected that commercially available high-frequency FET-MESFET will be the next device, produced serially.

Due to the large bandgap, high thermal conductivity, high thermal, chemical and radiation resistance, $\mathrm{SiC}$ was considered primarily as a promising material for power electronics. At the same time, silicon carbide has the ability to crystallize in different modifications 
(polytypes) that have the same chemical composition but different electrical parameters. This makes silicon carbide a promising material in terms of creating different types of heterostructures as well.

The existence of various crystalline modifications of $\mathrm{SiC}$ was discovered in (Baumhauer, 1912). Later, this phenomenon was called polytypism, i.e., polymorphisms in the single direction (Schneer, 1955). Silicon carbide is among the best example of polytype compounds.

Actually, the term "polytypism" has been introduced specifically to it, due to the fact that different crystalline forms of $\mathrm{SiC}$ are very similar to each other structurally. Currently, there are more than 200 known crystal modifications of SiC (Verma and Krishna, 1966).

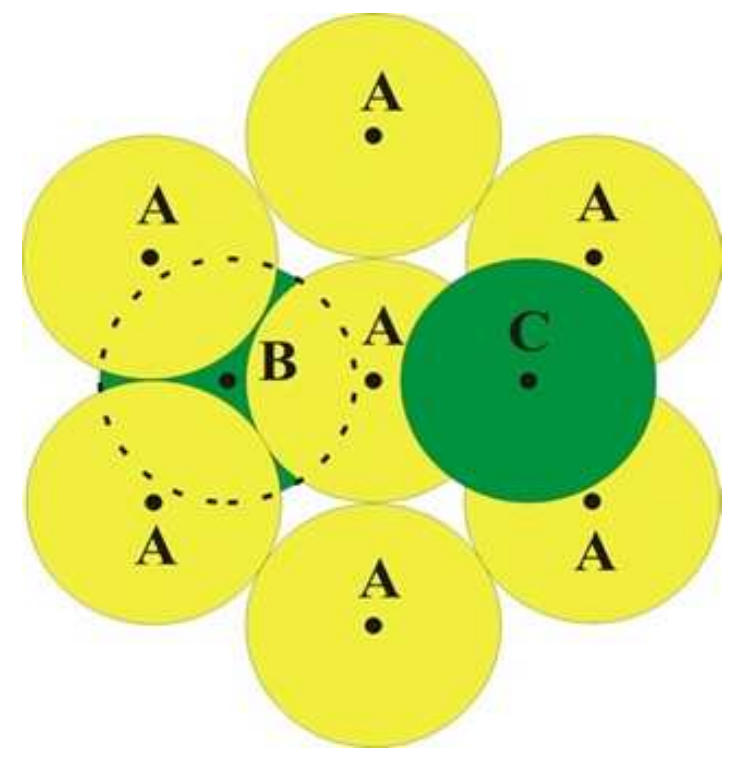

Fig. 2. Scheme of atom centers positions in the various layers crystal of lattice

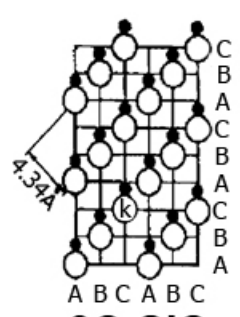

3C-SiC

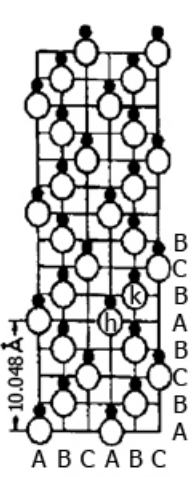

$4 \mathrm{H}-\mathrm{SiC}$

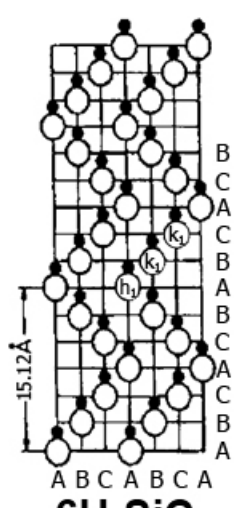

$6 \mathrm{H}-\mathrm{SiC}$

Fig. 3. Periodicity of the $\mathrm{SiC}$ crystal lattice of different polytypes

Figure 2 shows the positions of the atoms centers in a dense spherical packing. If the centers of all spheres in first layer are located in the points $\mathrm{A}$, then for the second layer the position of the centers at points $\mathrm{B}$ or $\mathrm{C}$ are already possible. Which of the possible positions will be occupied by the atoms in the second and subsequent layers determines the structure of the polytype.

To characterize the polytype the Ramsdell notation is also used often (Ramsdell, 1947). It consists of a natural number equal to the number of layers in the period in the direction, perpendicular to the base plane (Fig. 3) and an alphabetic character, characterizing the syngony of Bravais lattice: C-cubic, H-hexagonal, R-rhombohedral, for example, $3 \mathrm{C}, 4 \mathrm{H}, 6 \mathrm{H}$.

\section{PROSPECTS OF 3C-SIC IN POWER ELECTRONICS}

Among more than two hundred of silicon carbide polytypes one of the most interesting is the cubic polytype 3C-SiC. It has a maximum mobility of 1200 $\mathrm{cm}^{2} / \mathrm{V}$ sec (Levinshtein et al., 2001), among SiCpolytypes, the value of which does not depend on crystallographic direction. This greatly simplifies the manufacturing technology of power devices, because does not require precise positioning of the plates to the apparatus substructures. The magnitude of the bandgap substantially depends on the polytype and varies from $2.39 \mathrm{eV}$ for $3 \mathrm{C} \mathrm{SiCeV}$ and to $3.3 \mathrm{eV}$ for $2 \mathrm{H}-\mathrm{SiC}$. Thus, the difference in the values of the forbidden zones $(\Delta \mathrm{Eg}$ $[\mathrm{HC}])$ between a Cubic (3C) and pure Hexagonal $(2 \mathrm{H})$ SiCpolytypes is $\sim 0.9 \mathrm{eV}$.

Other parameters of $3 \mathrm{C}-\mathrm{SiC}$ (critical electric field, the maximum operating temperature, electrons saturation velocity and thermal conductivity) are differ slightly from the parameters of the hexagonal polytypes (Table 1).

Heterojunctions are the contacts between two semiconductors with different chemical nature or two different crystal polytypes of one semiconductor. The latter are called hetero-polytype.

From the point of view of power devices production technology the hetero-polytype structures are characterized by the following advantages:

- Lack of heteropair component mutual diffusion

- A slight mismatch in the lattice constants

- The same chemical properties

- The possibility of creating a heterojunction in alredy grown structure 
Table 1. Selected properties of $\mathrm{SiC}$ of different polytypes

\begin{tabular}{|c|c|c|c|c|}
\hline Parameter & $2 \mathrm{H}-\mathrm{SiC}$ & $4 \mathrm{H}-\mathrm{SiC}$ & $6 \mathrm{H}-\mathrm{SiC}$ & $3 \mathrm{C}-\mathrm{SiC}$ \\
\hline Stacking order & $\mathrm{AB}$ & $\mathrm{ABCB}$ & ABCACB & $\mathrm{ABC}$ \\
\hline Jagodzinskii notation & $\mathrm{h}$ & $\mathrm{hc}$ & hec & $\mathrm{c}$ \\
\hline Percentage "hexagonality", $\gamma(\%)$ & 100 & 50 & 33 & 0 \\
\hline Lattice constant $(\AA)$ & $\begin{array}{l}\mathrm{a}=3.076 \\
\mathrm{c}=5.048\end{array}$ & $\begin{array}{l}\mathrm{a}=3.073 \\
\mathrm{c}=10.053\end{array}$ & $\begin{array}{l}\mathrm{a}=3.08 \\
\mathrm{c}=15.117\end{array}$ & 4.34 \\
\hline Band gap (eV) & 3.33 & 3.26 & 3 & 2.39 \\
\hline Thermal conductivity $\left(\mathrm{W} \mathrm{cm}^{-1}{ }^{\circ} \mathrm{C}^{-1}\right)$ & & $3-4$ & $3-4$ & $3-4$ \\
\hline 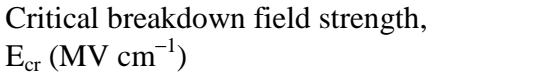 & & $2-3$ & $2-3$ & $>1.5$ \\
\hline $\begin{array}{l}\text { Electron mobility, } \\
\mu_{\mathrm{n}}\left(\mathrm{cm}^{2} \mathrm{~V}^{-1} \mathrm{~s}^{-1}\right)(300 \mathrm{~K})\end{array}$ & & $\leq 850$ & $\leq 450$ & $\leq 1000$ \\
\hline Saturation rate, $\mathrm{V}_{\mathrm{s}}\left(\times 10^{7} \mathrm{~cm} \mathrm{sec}^{-1}\right)$ & & 2 & 2 & 2.7 \\
\hline Hole mobility, $\mu_{\mathrm{p}}\left(\mathrm{cm}^{2} \mathrm{~V}^{-1} \mathrm{sec}^{-1}\right)(300 \mathrm{~K})$ & & $\leq 120$ & $\leq 100$ & $\leq 40$ \\
\hline
\end{tabular}

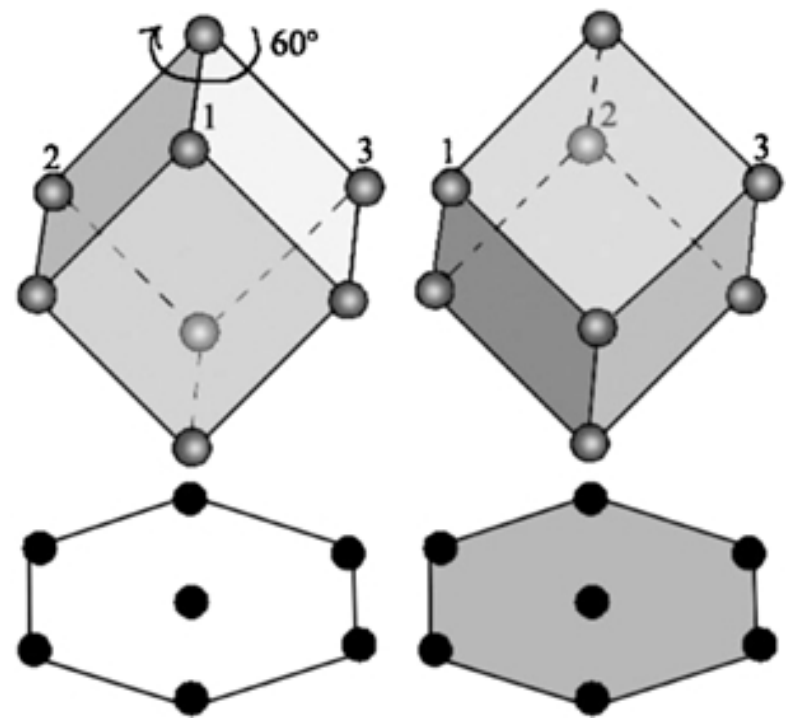

Fig. 4. Scheme of integration of $3 \mathrm{C}-\mathrm{SiC}$ cubic lattice into a hexagonal lattice

The most promising is the creation of heterostructures between cubic and one of hexagonal $\mathrm{nH}-\mathrm{SiC}$ silicon carbide polytypes. To imagine the incorporation of a cubic lattice in a hexagonal one, you should look down on the cube standing on one of its vertices. The projection of this cube on the horizontal plane will have the form of a hexagon (Fig. 4). Wherein the growing layer of $3 \mathrm{C}-\mathrm{SiC}$ will have a different crystal orientation than $\mathrm{nH}-\mathrm{SiC}$, used for the growth of substrate. If the initial hexagonal substrate had the orientation of (0001), the grown epitaxial layer will have an orientation of (111).

These crystallographic features of 3C-SiC layers growing, based on $\mathrm{nH}-\mathrm{SiC}$ substrates, lead to the so- called "pseudomorphic growth" (Fissel et al., 2000; Takagi et al., 2004). This means that the lattice constants of cubic and hexagonal polytypes are practically identical (lattice mismatch $<0.1 \%$ ) in the plane of growth. In the same time in the direction, perpendicular to the plane of growth, the lattice constants of the cubic and hexagonal polytypes will be different. It shows the theoretical possibility of obtaining near-perfect heterostructures between SiCpolytypes. Thus, the 3C$\mathrm{SiC}$ polytype is the most interesting.

\section{METHODS OF GROWING LAYERS AND BULK CRYSTALS OF 3C-SIC}

Lely method and modified Lely method, used for the obtainment of bulk crystals of $\mathrm{SiC}$ hexagonal polytypes, do not allow to grow $3 \mathrm{C}-\mathrm{SiC}$. In the $70 \mathrm{~s}$ of past century, the technology of producing monocrystals of 3C-SiC by thermal decomposition of trichlorosilane in hydrogen on a heated graphite substrate. However, this method did not allow obtaining crystals with sizes more than a few millimeters. Later, the technology of gas-phase epitaxy of 3C-SiC layers on the surface of silicon substrates was proposed. With this procedure it is possible to obtain the cubic silicon carbide layers of a larger area, but due to the significant mismatch of crystal lattices $(\sim 20 \%)$ and low growth temperature, limited by silicon melting point, the structural perfection of the produced layers remains low. It is not possible to apply the obtained 3C-SiC layers for the industrial production of semiconductor devices.

Alternative technology of growing the epitaxial layers of cubic silicon carbide is the Sublimation Epitaxy in Vacuum (SEV) 3C-SiC based on substrates of hexagonal polytypes $4 \mathrm{H}-\mathrm{SiC}, 6 \mathrm{H}-\mathrm{SiC}$. Previously, it was shown that for obtainment of thick epitaxial layers of $3 \mathrm{C}$-SiC with 
good structural perfection based on substrates of different hexagonal silicon carbide polytypes (Lebedev, 2007) with area of $\sim 0,5-0,8 \mathrm{~cm}^{2}$.

SEV method actually is a simplified high-temperature option of molecular beam epitaxy. The advantages of this method include:

- Epitaxy is performed at temperatures of 2100-2300 K, which is a more "natural" conditions for the growth of $\mathrm{SiC}$ crystals (spontaneous birth of $\mathrm{SiC}$ crystals on the walls of the graphite furnace is observed at 2500-2800 $\mathrm{K})$ and leads to a sharp decrease in the probability of structural defects formation

- SEV method allows to perform the sublimation etching "in situ" before growth to obtain atomically smooth surface and, as a result, get a perfect interface between the epitaxial layers

- Growth occurs in a high vacuum, which reduces uncontrolled doping and its influence on the process of hetero-polytypeepitaxy

Using the SEV method the homo-epitaxial p-n 3C$\mathrm{SiC}$ structures, based on $6 \mathrm{H}-\mathrm{SiC}$ substrates were obtained (Lebedev et al., 2003). A disadvantage of sublimation epitaxy in general and SEV in particular, is that the growth source is not renewed in the process of growth. With the passage of time this leads to changes in the $\mathrm{Si} / \mathrm{C}$ ratio in a growth zone and as a result, to poor controllability of epitaxy process. This can lead to appearance of $\mathrm{SiC}$ layers, which have finely twinned structure or to formation of lightly doped regions of p3C-SiC inside n-3C-SiC layer (Savkina et al., 2002; 2003). Nevertheless, the possibility of obtaining highquality epitaxial $3 \mathrm{C}-\mathrm{SiC}$ layers, based on $6 \mathrm{H}-\mathrm{SiC}$ substrates, polytype-homogeneous, thick (>100 m), of good structural perfection and with a minimum diameter of $25 \mathrm{~mm}$ is shown. Given the reach of growth rates $\sim 200 \mathrm{~m} \mathrm{~h}^{-1}$, the thickness of these layers during multiple processes can be increased to a size typical for bulk SiC ingots.

More promising is the use of this structures as seeds for growing ingots of bulk $3 \mathrm{C}-\mathrm{SiC}$ by modified method Lely, where the growth rate still several times higher. Such ingot can further be separated into monocrystalline substrate with the help standard techniques, which is used for producing the bars of hexagonal silicon carbide. Thus, there are prerequisites for the development of technology for producing bulk crystals of 3C-SiC for commercial use.

\section{CONCLUSION}

It should be expected that hetero-polytype structures will have a higher structural perfection than heterojunctions between semiconductors with different chemical nature. $\mathrm{SiC}$ is noyable among other polytype compounds as by having a large number of stable polytypes, by a large difference in their electrophysical properties and by high thermal, chemical and radiation resistance. Thus, we can assume that the creation of devices based on $\mathrm{SiC}$ hetero-polytype structures will be one of the most important trends in semiconductor electronics in the near future.

\section{FINDINGS}

In recent years a considerable progress in the development of power devices, based on SiC, including microwave range was achieved. Works in this direction are stimulated by the unique electro-physical properties of silicon carbide: High critical strength of the field (breakdown field), high thermal conductivity, high electrons saturation velocities, the ability to operate at high temperatures. The main problem hindering the widespread commercialization of power devices made of silicon carbide is the degradation of p-n structures during the passing of a direct current of high density. The reason to this is the formation of cubic SiC layers inside the hexagonal due to the displacement of an atom from the hexagonal positions of crystal lattice to cubical. This occurs at a value of direct current, sufficient to overcome the barrier, which corresponds to a displacement of an atom in a different position. Natural is the assumption that this effect will be absent in hetero-polytype structures of $3 \mathrm{C}-6 \mathrm{H} \mathrm{SiC}$, therefore the cubical silicon carbide polytype is the most promising material for the manufacturing of power electronics devices. However, this requires experimental confirmation.

\section{ACKNOWLEDGEMENT}

This article was prepared as part of the "1000 laboratories" program with the support of SaintPetersburg National Research University of Information Technologies, Mechanics and Optics (University ITMO).

\section{REFERENCES}

Baumhauer, H., 1912. Uber die krystalledes carborundums. Z. Kristallogr, 50: 33-38. DOI: 10.1524/zkri.1912.50.1.33 
Bergman, J.P., H. Lendenmann, P.A. Nilsson, U. Lindefelt and P. Skytt, 2001. Crystal defects as source of anomalous forward voltage increase of $4 \mathrm{H}-\mathrm{SiC}$ diodes. Mater. Sci. Forum, 353-356: 299-302. DOI: 10.4028/www.scientific.net/MSF.353-356.299

Cooper, J.A., M.R. Melloch, J.M. Woodall, J. Spitz and K.J. Schoen et al., 1998. Recent advances in SiC power devices. Mater. Sci. Forum, 268: 895-895-900. DOI: 10.4028/www.scientific.net/MSF.264-268.895

Fissel, A., B. Schroter, U. Kaiser and W. Richter, 2000. Advances in the molecular-beam epitaxial growth of artificially layered heteropolytypic structures of $\mathrm{SiC}$. Applied Phys. Lett., 77: 2418-2420. DOI: 10.1063/1.1311955

Lebedev, A.A., A.M. Strel'chuk, D.V. Davydov, N.S. Savkina and A.S. Tregubova et al., 2003. 3C-SiC p-n structures grown by sublimation on $6 \mathrm{H}-\mathrm{SiC}$ substrates. Semiconductors, $\quad 37$ : 482-484. DOI: $10.1134 / 1.1568473$

Lebedev, A.A., 2007. Investigation of thick 3C-SiC epilayers obtained by the sublimation method on $6 \mathrm{H}$ SiC substrates. FTP, 41: 273-275.

Levinshtein, M.E., S.L. Rumyantsev and M.S. Shur, 2001. Editors: "Properties of Advanced Semiconductor Materials: GaN, AlN,InN, BN, SiC, SiGe". 1st Edn., John Wiley and Sons, Inc., ISBN10: 0471358274, pp: 194.

Mao, M.S., S. Limpijumnong and W.R.L. Lambrecht, 2001. Stacking fault band structure in $4 \mathrm{H}-\mathrm{SiC}$ and its impact on electronic devices. Applied Phys. Lett., 79: 4360-4362. DOI: 10.1063/1.1427749
Ramsdell, L.S., 1947. Studies on silicon carbide. Am. Mineral, 32: 64-71.

Savkina, N., A. Tregubova, M. Scheglov, V. Soloviev and A. Volkova et al., 2002. Characterization of $3 \mathrm{C}-\mathrm{SiC}$ epilayers grown on $6 \mathrm{H}-\mathrm{SiC}$ substrates by vacuum sublimation. Mater. Sci. Eng. B, 92: 317320. DOI: 10.1016/S0921-5107(01)01053-4

Savkina, N.S., A.M. Strel'chuk, L.M. Sorokin, G.N. Mosina and A.S. Tregubova et al., 2003. Characterization of 3C-SiC/6H-SiC heterostructures grown by vacuum sublimation. Mater. Sci. Forum, 293: 433-436. DOI: 10.4028/www.scientific.net/MSF.433-436.293

Schneer, C.J., 1955. Polymorphism in one dimension. Acta Crystallogr, 8: 279-284. DOI: 10.1107/S0365110X55000893

Takagi, H., T. Nishiguchi, S. Ohta, T. Furusho and S. Ohshima et al., 2004. Crystal growth of $6 \mathrm{H}-\mathrm{SiC}$ (01 14) on 3C-SiC (001) substrate by sublimation epitaxy. Mater. Sci. Eng., 457-460: 289-292. DOI: 10.4028/www.scientific.net/MSF.457-460.289

Verma, A.R. and P. Krishna, 1966. Polymorphism and Polytypism in Crystals. 1st Edn., Wiley, New York, ISBN-10: 978-0471906438, pp: 274.

Zeither, G. and D. Theeis, 1981. A new degradation phenomenon in blue light emitting silicon carbide diodes. IEEE Trans. Electron. Dev., 28: 425-427. DOI: 10.1109/T-ED.1981.20359 